\title{
Study on the effects of milling time and sintering temperature on the sinterability of forsterite $\left(\mathrm{Mg}_{2} \mathrm{SiO}_{4}\right)$
}

\author{
Yoke Meng TAN, Chou Yong TAN, ${ }^{\dagger}$ Singh RAMESH, Yee Ching TEH, Yern Chee CHING, \\ Nilar LWIN, Boon Kar YAP* and Dinesh AGRAWAL** \\ Centre of Advance Manufacturing and Materials Processing, Department of Mechanical Engineering, \\ Faculty of Engineering, University of Malaya, 50603 Kuala Lumpur, Malaysia \\ *Department of Electronics and Communication, College of Engineering, Universiti Tenaga Nasional, \\ Km-7, Jalan Ikram-UNITEN, 43009 Kajang, Selangor, Malaysia \\ ${ }^{* *}$ Microwave Processing and Engineering Centre, 107 Materials Research Technology, The Pennsylvania State University, \\ University Park, PA 16802, USA
}

\begin{abstract}
Synthesis of phase-pure forsterite $\left(\mathrm{Mg}_{2} \mathrm{SiO}_{4}\right)$ is a challenging process that requires multiple steps including careful heat treatment and ball milling. In this work, the effects of temperature, time and ball milling duration in synthesizing forsterite powder were investigated. A comparison of 1000 and $1200^{\circ} \mathrm{C}$ heat treatment temperature with $1 \mathrm{~min}, 1$, and $2 \mathrm{~h}$ of holding time during heat treatment was conducted. In addition, 1, 5, 7, and $10 \mathrm{~h}$ of milling time were selected as variables to identify optimum conditions for completion of reaction in forming pure forsterite powder. Based on the $\mathrm{X}$-ray diffraction results, $1200^{\circ} \mathrm{C}$ heat treatment, $2 \mathrm{~h}$ of holding time, and $7 \mathrm{~h}$ of milling successfully produced single phase forsterite powders with crystallite size of $41 \mathrm{~nm}$. The forsterite powder was compacted and sintered at temperatures ranging from 1200 to $1500^{\circ} \mathrm{C}$. The highest hardness and fracture toughness of 7.11 GPa and $4.88 \mathrm{MPa} \mathrm{m}^{1 / 2}$ were achieved when sintered at $1400^{\circ} \mathrm{C}$, respectively. Meanwhile, the highest relative density of $91 \%$ was obtained for the sample sintered at $1500^{\circ} \mathrm{C}$.
\end{abstract}

(02015 The Ceramic Society of Japan. All rights reserved.

Key-words : Forsterite, Heat treatment, Ball milling, Solid-state reaction, Sintering, Bioceramic

[Received April 15, 2015; Accepted September 10, 2015]

\section{Introduction}

Forsterite $\left(\mathrm{Mg}_{2} \mathrm{SiO}_{4}\right)$ is a member of the olivine family of crystals and has potential applications in biomedical field. ${ }^{1)}$ Forsterite has recently become a popular for research for bone implants because of its good biocompatibility and mechanical properties. ${ }^{2)}$ Forsterite has better fracture toughness $\left(K_{\mathrm{IC}}=2.4 \mathrm{MPa} \mathrm{m}^{1 / 2}\right)$ than hydroxyapatite, HA $\left(K_{\mathrm{IC}}=0.6-1.0 \mathrm{MPa} \mathrm{m}^{1 / 2}\right){ }^{3), 4)}$ Having high fracture toughness in biomedical application is important to safeguard the effectiveness in resisting crack propagation, and ensuring the reliability of implant. Therefore, synthesizing a phase-pure forsterite is crucial because the secondary phases will decrease the strength and reliability of the sintered ceramic. ${ }^{5-7)}$

Most common secondary phases include periclase $(\mathrm{MgO})$ and enstatite $\left(\mathrm{MgSiO}_{3}\right),{ }^{8)-10)}$ and they can be eliminated by careful heat treatment. In order to avoid secondary phases the reaction between stoichiometric precursors must be completed by sufficient heating and duration during heat treatment. ${ }^{1), 11)}$ The synthesis of phase pure forsterite involves a sluggish diffusion process; the efficiency of such diffusion process can be correlated with the crystallite size. ${ }^{8)-10), 12)}$ Complete sintering and microstructure development are crucial in enhancing the mechanical properties of forsterite. However, during sintering, high temperature contributes to excessive grain growth and causes pores to be entrapped within large grains, affecting the mechanical properties of forsterite ceramic. Hence, this work investigates the effect of temperature, time, and ball milling duration on the phase purity and its stability; the sinterability of bulk forsterite samples.

Corresponding author: C. Y. Tan; E-mail: chouyong@um.edu.my

\section{Experimental procedures}

2.1 Preparation of forsterite powder via solid state reaction

Forsterite powders were prepared by solid state reaction using stoichiometric amounts of $\mathrm{MgO}$ (Merck, 97\%) and $\mathrm{Mg}_{3} \mathrm{Si}_{4} \mathrm{O}_{10^{-}}$ $(\mathrm{OH})_{2}$ (Sigma-Aldrich, 99\%), at a weight ratio of 1:1.8825. These precursors were weighed accordingly with an accuracy of four decimal points (Mettler Toledo, Switzerland) and mixed using an ultrasonic bath (Liarre, Italy). $\mathrm{MgO}$ was initially added into a beaker filled with $100 \mathrm{~mL}$ of ethanol as solvent, and then underwent ultrasonification for $2 \mathrm{~min}$. Subsequently, $\mathrm{Mg}_{3} \mathrm{Si}_{4} \mathrm{O}_{10}(\mathrm{OH})_{2}$ was added into the same beaker for ultrasonic process for another 2 min. A conventional table top ball mill was used to blend the ultrasonicated powders at $350 \mathrm{rpm}$ for $1,5,7$, and $10 \mathrm{~h}$, respectively. Zirconia ball with $3 \mathrm{~mm}$ diameter and polypropylene bottle of $500 \mathrm{ml}$ were used as the milling media and milling jar, respectively. Each batch of samples was then dried using an oven (Memmert) at $60^{\circ} \mathrm{C} / 24 \mathrm{hr}$, sieved, and heat-treated at 1000 and $1200^{\circ} \mathrm{C}$ for $1 \mathrm{~min}, 1$, and $2 \mathrm{~h}$ of holding time. The resultant powders were uni-axially pressed at $2.5 \mathrm{MPa}$ pressure to form green samples. Cold isostatic press at $200 \mathrm{MPa}$ was applied to the green samples, followed by sintering at different temperatures (1200 to $1500^{\circ} \mathrm{C}$, with $50^{\circ} \mathrm{C}$ interval) at a heating rate of $10^{\circ} \mathrm{C} / \mathrm{min}$ for $2 \mathrm{~h}$.

\subsection{Characterization of forsterite ceramics}

Phase analysis of all the samples was carried out using an Xray diffractometer (XRD) (Rigaku Gieger-Flex, Japan) operated at $35 \mathrm{kV}$ and $15 \mathrm{~mA}$, with $\mathrm{Cu}-\mathrm{K} \alpha$ as radiation source. A step scan of $0.02^{\circ}$ and scan speed of $0.5^{\circ} / \mathrm{min}$ was employed. The crys- 
tallite size of the synthesized powder (upon heat treatment) was measured using Scherrer equation by taking the highest peak observed at $36.4^{\circ},\left(\begin{array}{lll}2 & 1 & 1\end{array}\right)$ plane, to obtain the Full-Width Half Maximum value ${ }^{13)}$ with three samples.

Five samples for each parameter were used to measure the bulk density of forsterite by water immersion technique using Archimedes principle. The relative density was calculated by taking the theoretical density of forsterite as $\left.3.271 \mathrm{~g} \mathrm{~cm}^{-3} .{ }^{3}\right)$ Microhardness $(\mathrm{Hv})$ and fracture toughness $\left(K_{\mathrm{IC}}\right)$ of the samples were measured using Vickers hardness tester (HMV Shimadzu, Japan) upon grinding and polishing for a more reflective surface. The dwell time used for the indentation is $10 \mathrm{~s}$ with a load of $200 \mathrm{~g}$. Average value was taken from a population of 5. The fracture toughness value was calculated based on the equation taken from Niihara et al. [17]:

$$
K_{\mathrm{IC}}=0.203\left(\frac{c}{a}\right)^{-1.5} \operatorname{Hv}(a)^{0.5}
$$

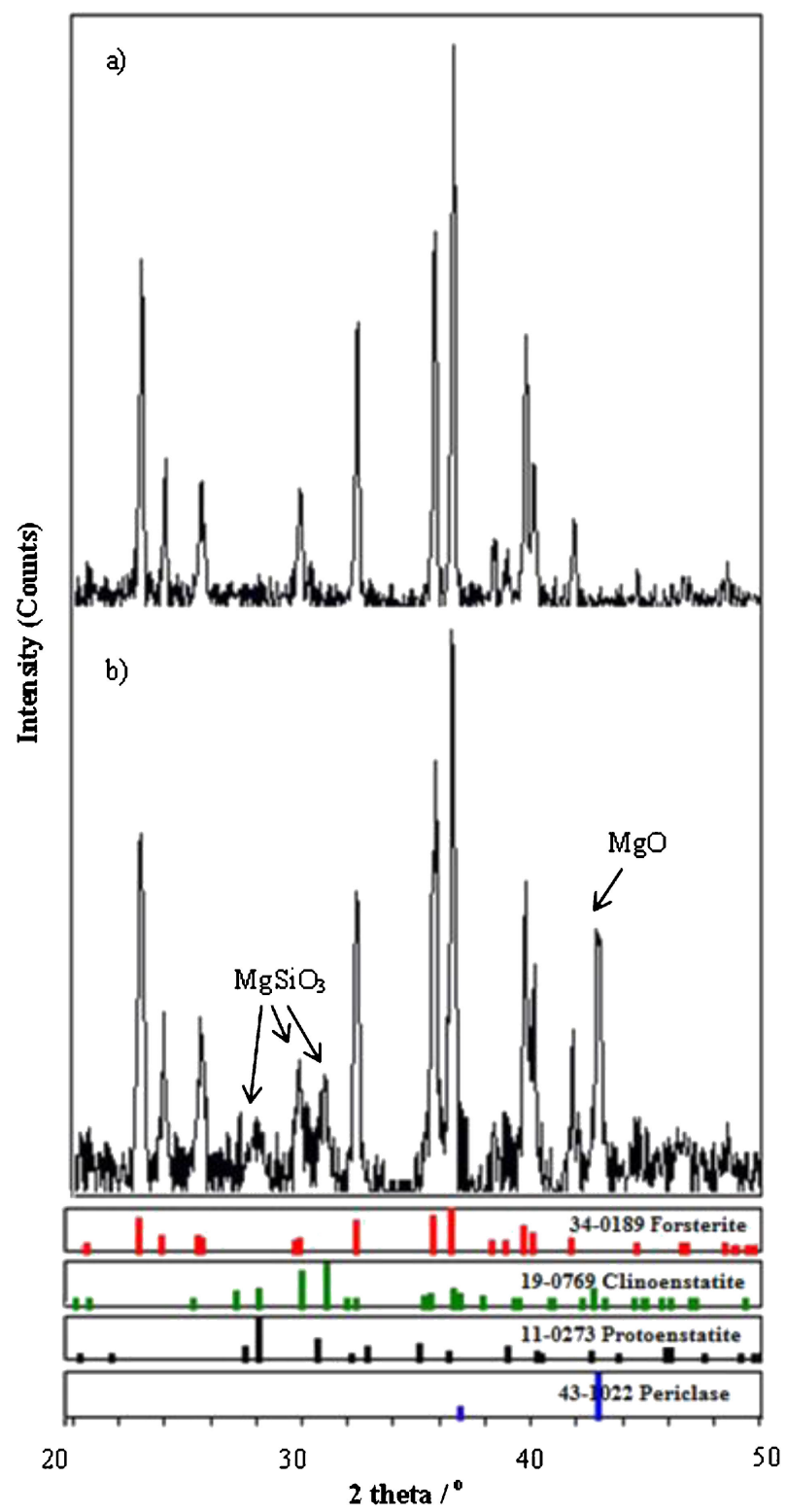

Fig. 1. XRD trace of samples ball milled for $10 \mathrm{~h}$ and heat-treated at (a) $1200^{\circ} \mathrm{C}$ and (b) $1000^{\circ} \mathrm{C}$ for $2 \mathrm{~h}$. Sample heat-treated at $1000^{\circ} \mathrm{C}$ contained secondary phases that consisted of $\mathrm{MgO}$ and $\mathrm{MgSiO}_{3}$ whereas $1200^{\circ} \mathrm{C}$ is pure forsterite powder. whereby, $c$ is characteristic crack length and $a$ is half-diagonal of the indent. The microstructures of the sintered forsterite samples were examined by using a scanning electron microscope (SEM, Philip). Thermal etching was conducted at $50^{\circ} \mathrm{C}$ lower than its corresponding sintering temperature for $30 \mathrm{~min}$ to delineate the grains before running SEM analysis.

\section{Results and discussion}

$\mathrm{XRD}$ analysis of the two samples subjected to heat treatment at two temperatures is presented in Fig. 1. Secondary phases $(\mathrm{MgO}$ and $\mathrm{MgSiO}_{3}$ ) were found in the sample heat-treated at $1000^{\circ} \mathrm{C}$ for $2 \mathrm{~h}$. However, phase-pure forsterite was obtained only at $1200^{\circ} \mathrm{C}$. This result indicates that a high temperature of $1200^{\circ} \mathrm{C}$ is required to ensure a complete reaction occurring between the starting precursors to form single phase forsterite.

Effect of holding time in the formation of forsterite during heat treatment of the powder mixture was also investigated. In Fig. 2, the XRD patterns of the samples heat-treated at $1200^{\circ} \mathrm{C}$ for $1 \mathrm{~min}$ and $1 \mathrm{~h}$ are presented. They showed the presence of $\mathrm{MgO}$ and $\mathrm{MgSiO}_{3}$ in the sample with 1 min holding time,

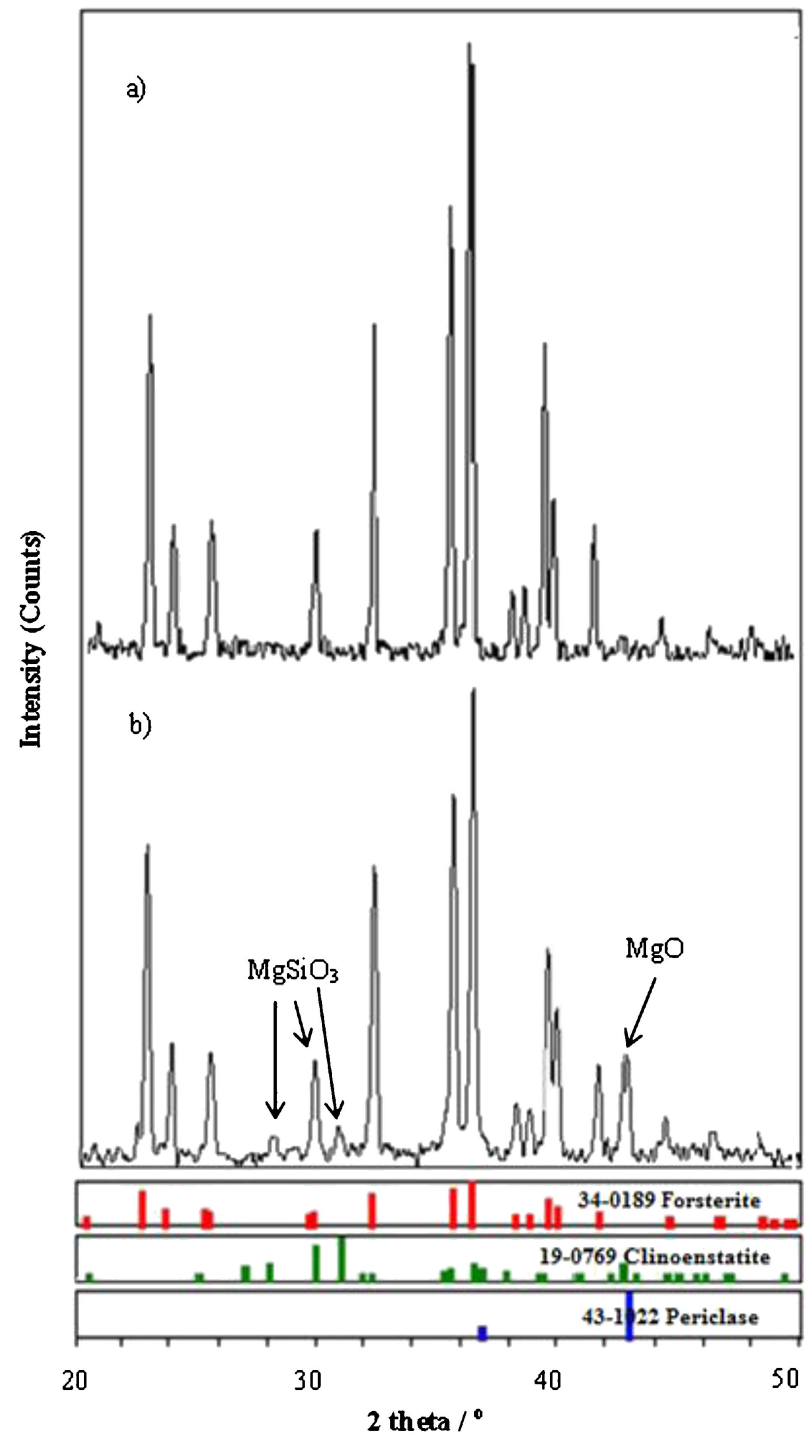

Fig. 2. XRD traces of powders ball milled for $10 \mathrm{~h}$ and heat-treated at $1200^{\circ} \mathrm{C}$ for (a) $1 \mathrm{~h}$ and (b) $1 \mathrm{~min}$. Sample with $1 \mathrm{~h}$ holding time successfully produced pure forsterite while $1 \mathrm{~min}$ of holding time contained $\mathrm{MgO}$ and $\mathrm{MgSiO}_{3}$. 


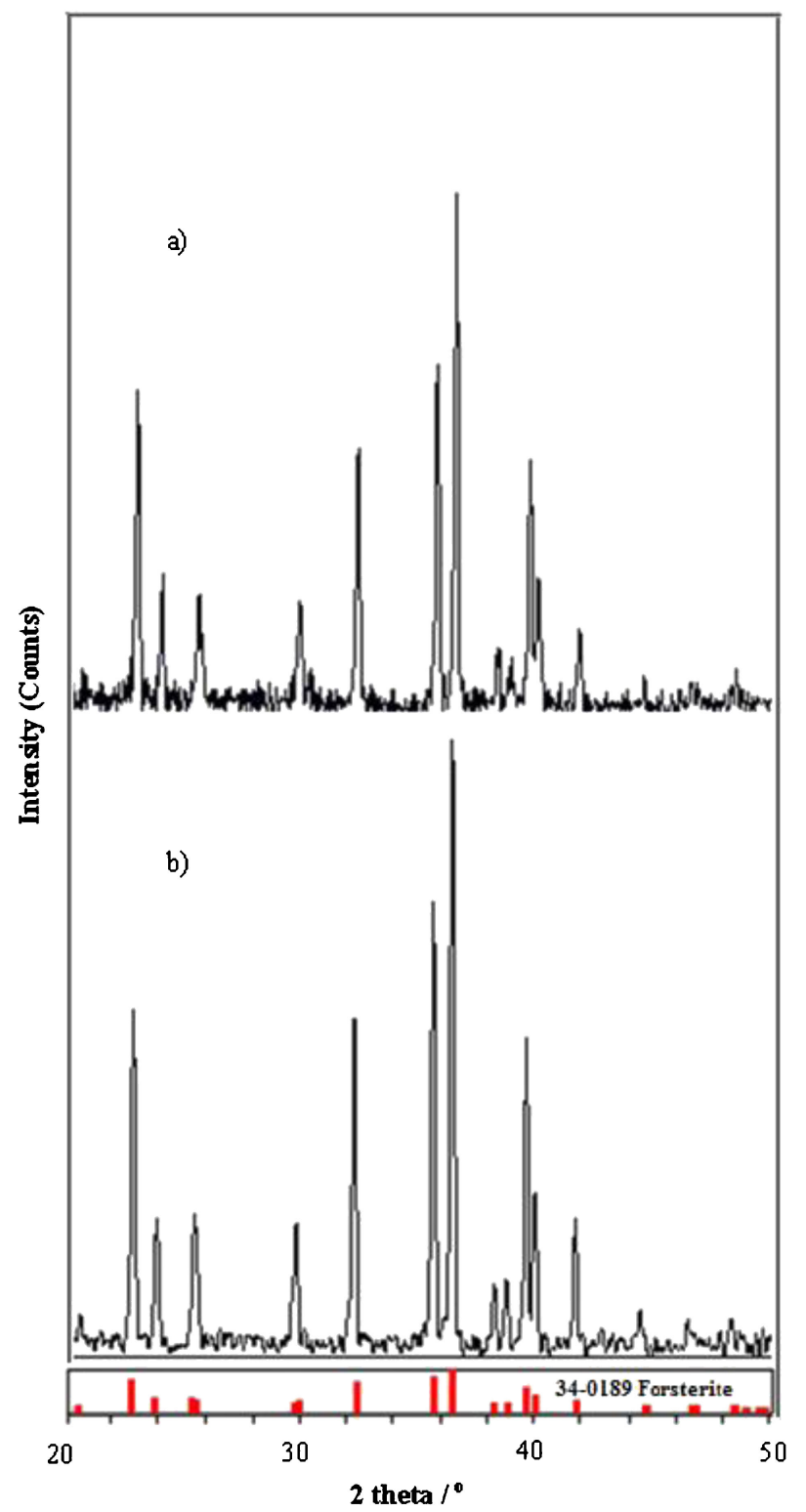

Fig. 3. XRD traces of powders ball milled for $10 \mathrm{~h}$ and heat-treated at $1200^{\circ} \mathrm{C}$ for (a) $1 \mathrm{~h}$ and (b) $2 \mathrm{~h}$. Both samples showed only pure forsterite phase.

whereas phase-pure forsterite was successfully formed at $1 \mathrm{~h}$ of holding time. As reported by another researcher, the formation of forsterite is a slow diffusion process between the precursors. ${ }^{2)}$ This experiment proved that adequate time is required for the reaction to complete. The comparison between 1 and $2 \mathrm{~h}$ of holding time is shown in Fig. 3. Heat treatment for $2 \mathrm{~h}$ resulted in higher crystallinity as compared with $1 \mathrm{~h}$ of holding time. Extension in milling duration further refined the crystallinity of forsterite powder.

The effect of ball milling time on the phase composition is shown in Fig. 4. The XRD results showed secondary phases for two different batches ball milled for 1 and $5 \mathrm{~h}$. Formation of secondary phases were observed for the samples milled for $1 \mathrm{~h}$, with definite peaks appearing at 28.1, 30.1, and $31.2^{\circ}$ for $\mathrm{MgSiO}_{3}$ and $42.9^{\circ}$ for $\mathrm{MgO}$, whereas the samples milled for $5 \mathrm{~h}$ showed only $\mathrm{MgO}$ peak. Single phase forsterite was successfully obtained when milled for $7 \mathrm{~h}$ [Fig. 4(b)]. The intensity of $\mathrm{MgO}$ and

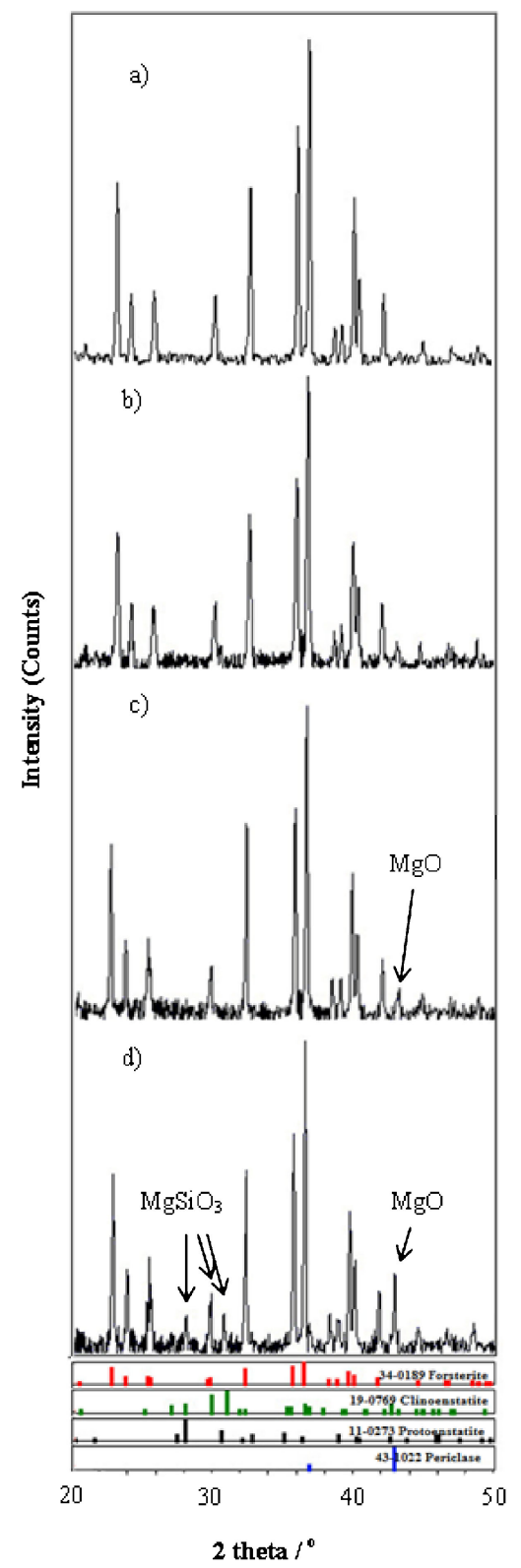

Fig. 4. XRD traces of forsterite powder milled for (a) $10 \mathrm{~h}$, (b) $7 \mathrm{~h}$, (c) $5 \mathrm{~h}$ and (d) $1 \mathrm{~h}$ and heat-treated at $1200^{\circ} \mathrm{C}$ for $2 \mathrm{~h}$. Samples with $1 \mathrm{~h}$ milling consisted of both secondary phases while $5 \mathrm{~h}$ of milling only possessed $\mathrm{MgO}$ peak. Both 7 and $10 \mathrm{~h}$ of milling samples are pure forsterite powder.

$\mathrm{MgSiO}_{3}$ peaks initially decreased, and then completely disappeared with increasing milling duration. This trend is in agreement with other researchers that claimed the importance of having ball mill process with sufficient duration to increase the reactivity between the two starting precursors. ${ }^{8)-12), 14)}$

The relationship between the milling duration and crystallite size was shown in Fig. 5. One hour of ball mill produced powder with crystallite size of $46 \mathrm{~nm}$, the size was $41 \mathrm{~nm}$ at $7 \mathrm{~h}$, and the crystallite size reduced to $34 \mathrm{~nm}$ at $10 \mathrm{~h}$ of milling. Crystallite size decreased with increasing milling duration because of the increase in surface area during the milling process, thereby promoting reactivity between the two precursors. Based on this result, it was discovered that the range of crystallite size required to produce phase-pure forsterite was established for future work. 
This result is in agreement with the findings investigated by Cheng et al. ${ }^{15)}$ who claimed that prolonged mechanical activation duration would produce finer nano-metric crystals.

Upon investigating the ideal heat treatment profile to produce phase-pure forsterite powder, samples were pressed and sintered under various sintering temperature. Figure 6 shows the XRD traces for forsterite bulk sintered from 1200 to $1500^{\circ} \mathrm{C}$ with $50^{\circ} \mathrm{C}$ intervals. During sintering process, no decomposition or chemical changes were observed for all samples. It is concluded that sintering process will not cause any adverse effect on the thermal stability of phase-pure forsterite.

Figure 7 shows the relationship between sintering temperature, relative density, and Vickers hardness of forsterite sample milled for $10 \mathrm{~h}$. An increasing trend on relative density was observed when the sintering temperature was increased. A steep increase in relative density was observed between 1200 to $1250^{\circ} \mathrm{C}$. However, as sintering temperature is increased to $1300^{\circ} \mathrm{C}$, the increment of relative density became less significant;

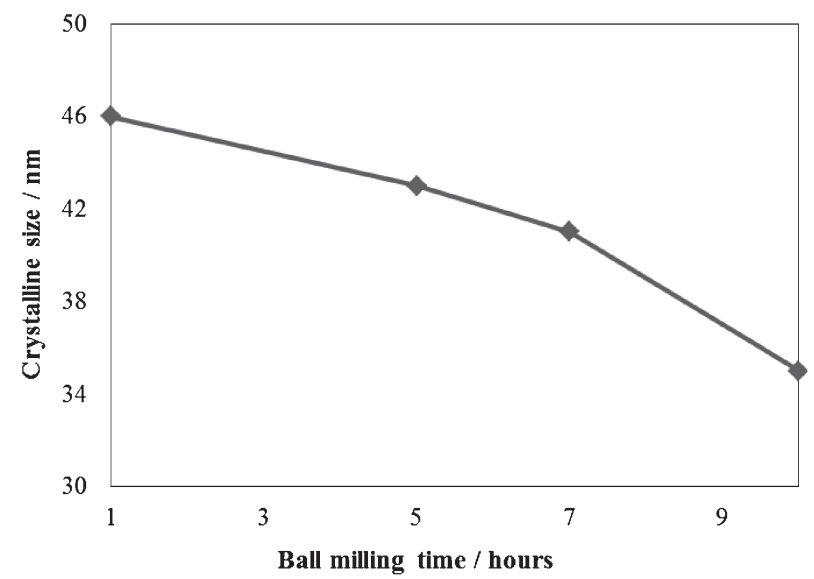

Fig. 5. Effect of ball milling time with crystallite size of forsterite powder heat-treated at $1200^{\circ} \mathrm{C}$ for $2 \mathrm{~h}$. A decreased in crystallite size was observed as the milling duration increased. the highest relative density of $91 \%$ was obtained at $1500^{\circ} \mathrm{C}$.

In the case of Vickers hardness, the hardness significantly increased from 1200 to $1250^{\circ} \mathrm{C}$ and attained the highest hardness of $7.11 \mathrm{GPa}$ at $1400^{\circ} \mathrm{C}$ before decreasing. SEM micrographs (Fig. 8) show that the decrease in hardness upon reaching $1400^{\circ} \mathrm{C}$ was because of grain coarsening. Figures $8(\mathrm{a})$ and $8(\mathrm{~b})$ show the appearance of porosity throughout the grain structure, affecting the densification. With increasing temperature, porosity began to reduce and taken over by grains that were continuously growing, thereby improving the density. Moreover, the densification of forsterite bulk was incomplete as it reached up to $91 \%$ at $1500^{\circ} \mathrm{C}$. Figure 9 shows the existence of entrapped porosity within the grains, causing incomplete densification.

Similar trend was observed regarding the effect of sintering temperature on both Vickers hardness and fracture toughness (Figs. 7 and 10). The highest fracture toughness value (4.88 $\mathrm{MPa} \mathrm{m}^{1 / 2}$ ) achieved at $1400^{\circ} \mathrm{C}$ in this study is higher than the fracture toughness value of $4.3 \mathrm{MPa} \mathrm{m}^{1 / 2}$ obtained by Kharaziha and Fathi. ${ }^{16)}$ In addition, this value $\left(4.88 \mathrm{MPa} \mathrm{m}^{1 / 2}\right)$ is within the range of fracture toughness of human bone ( 2 to $12 \mathrm{MPa} \mathrm{m}^{1 / 2}$ ), which makes nanocrystalline forsterite a good candidate for biomedical application. ${ }^{17)}$ However, beyond $1400^{\circ} \mathrm{C}$, the fracture toughness deteriorated, and this phenomenon was in agreement with that reported by $\mathrm{Ni}$ et al. ${ }^{12)}$ The deterioration of fracture toughness can be related to the Hall-Petch relationship. Upon reaching the critical grain size $(\sim 21 \mu \mathrm{m})$ at $1400^{\circ} \mathrm{C}$ of sintering temperature, any further growth of grain would adversely affect both the Vickers hardness and fracture toughness.

\section{Conclusion}

The effects of heat treatment (temperature and holding time) and ball milling duration on the formation of phase-pure forsterite were explained. Crystallite size has an important role in ensuring the formation of single phase forsterite because this factor affects the diffusivity between two precursors. The optimum conditions for producing single phase forsterite powder are $1200^{\circ} \mathrm{C} / 2 \mathrm{~h}$ for the diffusion process to complete. Extended holding hour during heat treatment will produce forsterite pow-
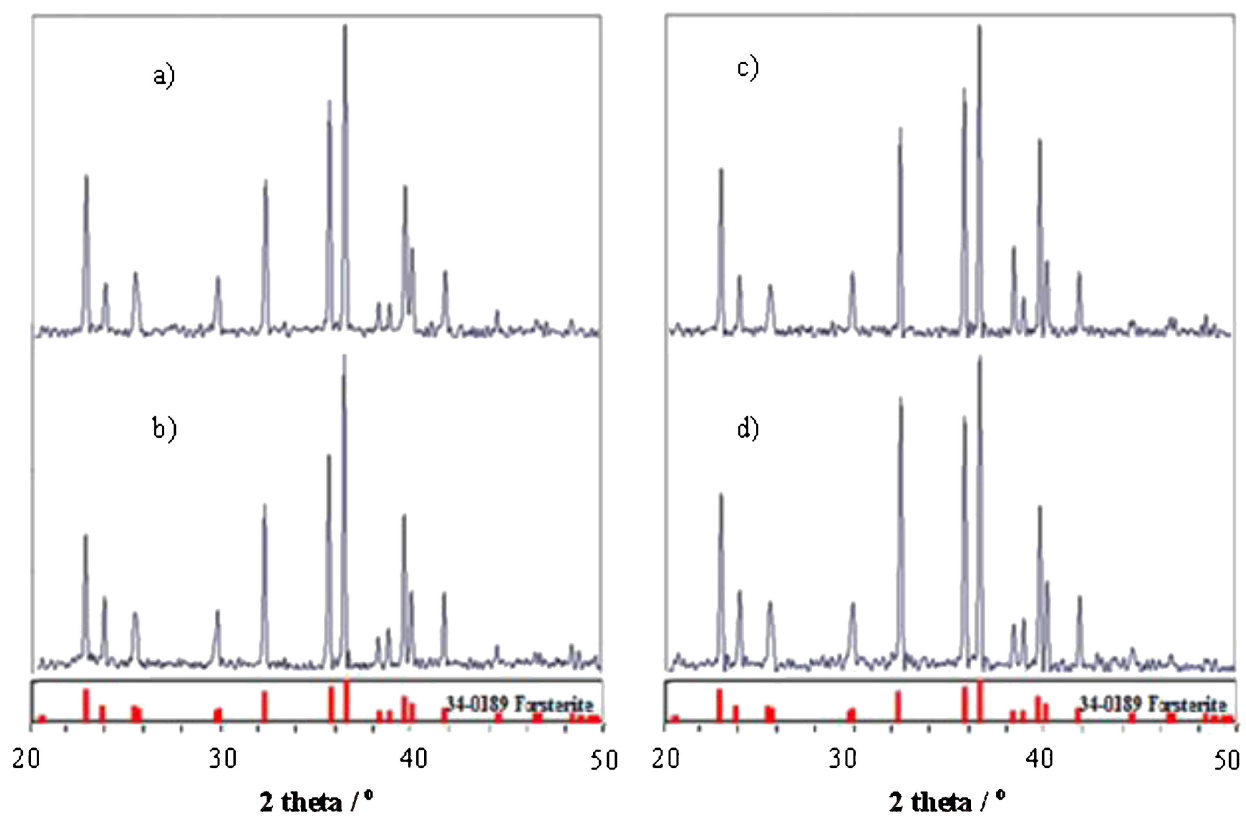

Fig. 6. XRD traces of forsterite bulk $\left(10 \mathrm{~h}\right.$ milling and heat-treated at $\left.1200^{\circ} \mathrm{C} / 2 \mathrm{~h}\right)$ sintered at (a) $1200^{\circ} \mathrm{C}$, (b) $1300^{\circ} \mathrm{C}$, (c) $1400^{\circ} \mathrm{C}$ and (d) $1500^{\circ} \mathrm{C}$ with $10^{\circ} \mathrm{C} / \mathrm{min}$ for $2 \mathrm{~h}$. All samples showed phase pure forsterite. 


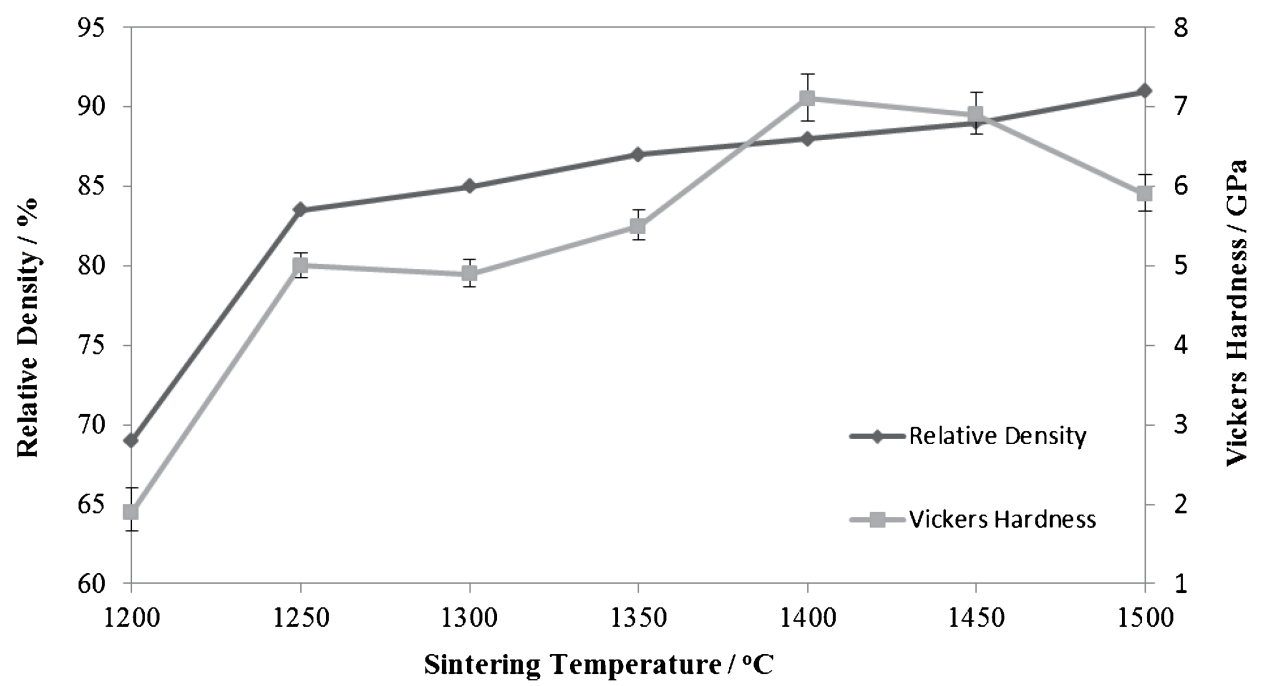

Fig. 7. Effect of sintering temperature on relative density and hardness of forsterite bulk milled for $10 \mathrm{~h}$ and heat-treated at $1200^{\circ} \mathrm{C}$ for $2 \mathrm{~h}$. Relative density of forsterite bulk is directly proportional to the sintering temperature while hardness value of forsterite bulk increased up until $1400^{\circ} \mathrm{C}$ before it began to decrease.
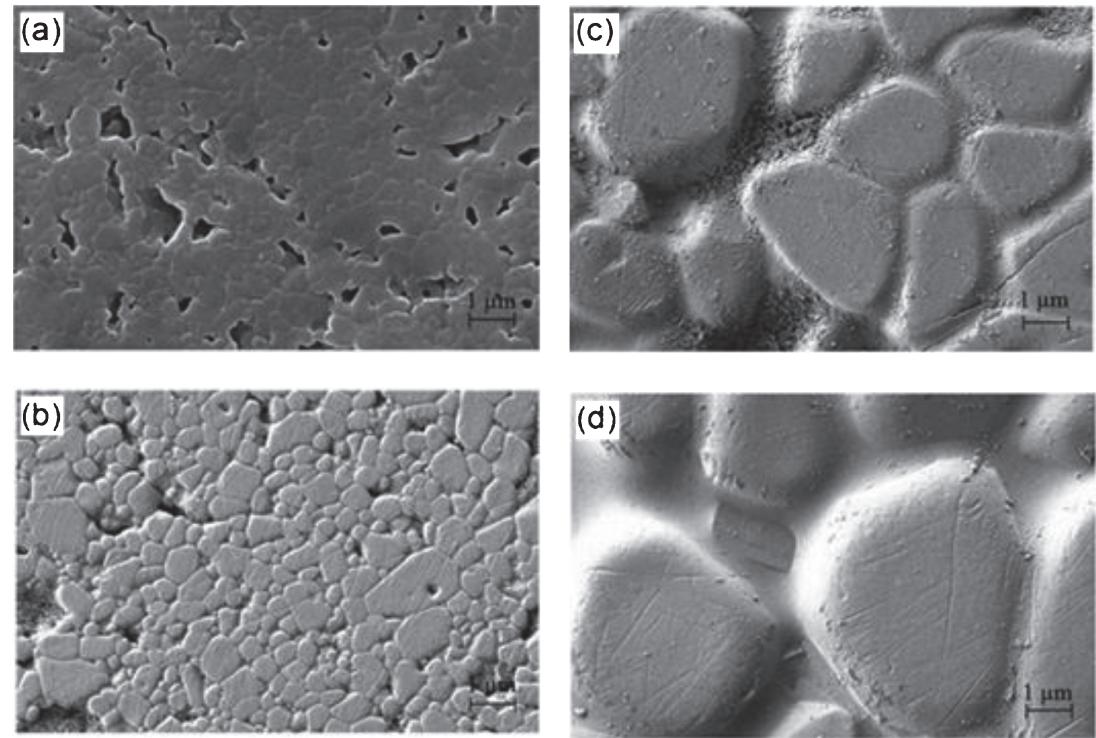

Fig. 8. Morphology of sintered forsterite milled for $10 \mathrm{~h}$ when sintered at (a) $1200^{\circ} \mathrm{C}$, (b) $1250^{\circ} \mathrm{C}$, (c) $1400^{\circ} \mathrm{C}$ and (d) $1500^{\circ} \mathrm{C}$ for $2 \mathrm{~h}$. Grain growth was observed as the temperature increases to promote densification as well as enhancement of the hardness of forsterite bulk. However, grain coarsening was observed for $1500^{\circ} \mathrm{C}$ samples.

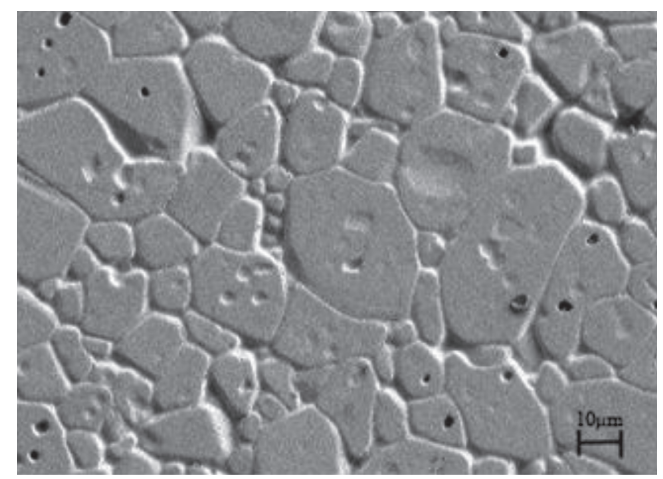

Fig. 9. Morphology of forsterite sample milled for $10 \mathrm{~h}$ sintered at $1500^{\circ} \mathrm{C}$ for $2 \mathrm{~h}$ with $250 \mathrm{X}$ magnification. Porosity was observed as the magnification was decreased to observe the condition of the grain at $10 \mu \mathrm{m}$ scale. der with higher crystallinity. Based on the findings, $7 \mathrm{~h}$ of ball milling duration is sufficient to produce a nanophase forsterite and further extension on the milling duration will reduce the crystalline size. The highest relative density obtained was $91 \%$ for the samples sintered at $1500^{\circ} \mathrm{C}$. The sample sintered at $1400^{\circ} \mathrm{C}$ had the highest Vickers hardness of $7.11 \mathrm{GPa}$ and decreased after surpassing $1400^{\circ} \mathrm{C}$. The incomplete densification of sintered forsterite samples was because of the entrapment of pores within the grains. A maximum fracture toughness of 4.88 $\mathrm{MPa} \mathrm{m}^{1 / 2}$ was achieved at $1400^{\circ} \mathrm{C}$ and began to reduce beyond $1400^{\circ} \mathrm{C}$ because of reverse Hall-Petch relationship. Moreover, the as-obtained value of fracture toughness surpasses the low limit of cortical bone range. Therefore, in terms of mechanical properties, forsterite ceramic can be the next choice after HA for load bearing applications. 


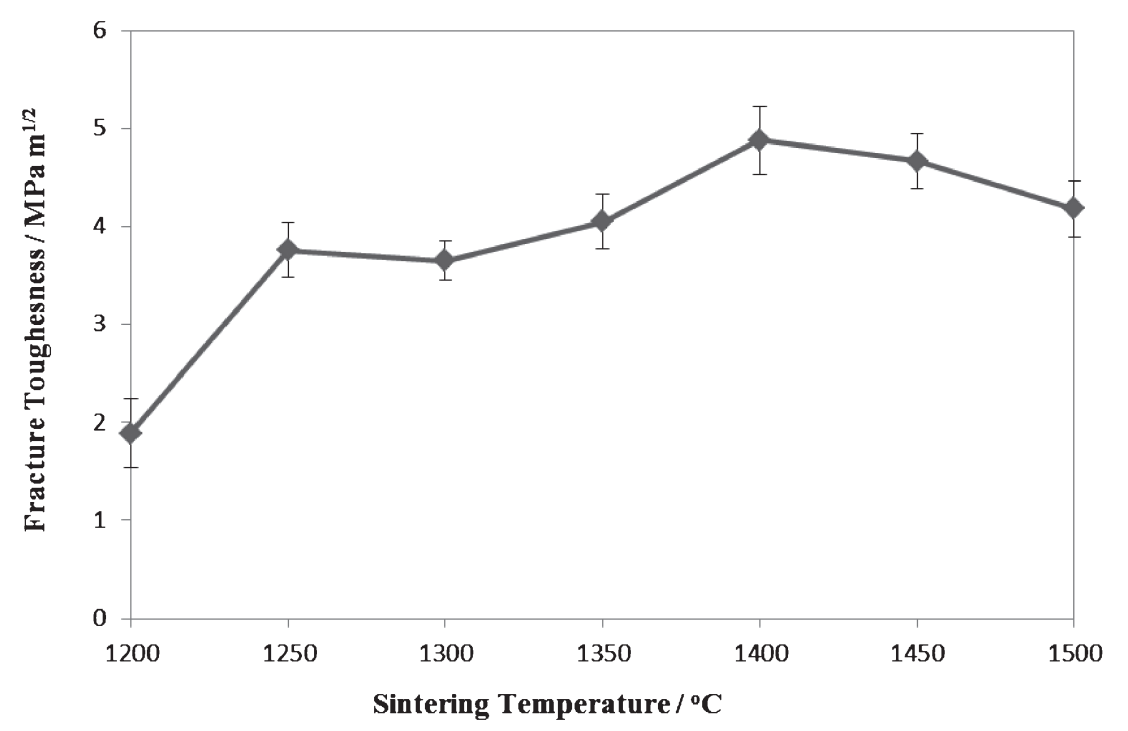

Fig. 10. Effect of sintering temperature ranging from 1200 to $1500^{\circ} \mathrm{C}$ with holding time of $2 \mathrm{~h}$ on the fracture toughness of forsterite bulk milled for $10 \mathrm{~h}$. A similar trend was observed for fracture toughness and hardness of forsterite samples as the sintering temperature increased. A reverse Hall-Petch relationship explained the phenomena of the decreased in fracture toughness after $1400^{\circ} \mathrm{C}$ sintering temperature.

Acknowledgement This study was supported under the HIR grant number B-16001-00-D000052, PRPUM grant number CG0112013, UMRG grant number RP024B-13AET, UMRG grant number RP011B-13AET, PPP grant number PG129-2014A and FRGS grant number FP029-2013A. The authors gratefully acknowledge University of Malaya and the Ministry of Higher Education Malaysia for the financial support.

\section{References}

1) F. Tavangarian and R. Emadi, Mater. Res. Bull., 45, 388-391 (2010).

2) S. Ramesh, A. Yaghoubi, K. Y. Sara Lee, K. M. Christopher Chin, J. Purbolaksono, M. Hamdi and M. A. Hassan, J. Mech. Behav. Biomed., 25, 63-69 (2013).

3) H. Ghomi, M. Jaberzadeh and M. H. Fathi, J. Alloys Compd., 509, 63-68 (2011).

4) W. Suchanek and M. Yoshimura, J. Mater. Res., 13, 94-117 (1998).

5) W. Mielcarek, D. Nowak-Wozny and K. Prociow, J. Eur. Ceram. Soc., 24, 3817-3821 (2004).

6) W. E. Lee and A. H. Heuer, J. Am. Ceram. Soc., 70, 349-360
(1987).

7) J. F. Sarve and F. A. Hummel, J. Am. Ceram. Soc., 55, 152$156(1962)$

8) F. Tavangarian and R. Emadi, J. Alloys Compd., 485, 648-652 (2009).

9) A. Douy, J. Sol-Gel Sci. Technol., 24, 221-228 (2002).

10) F. Tavangarian, R. Emadi and A. Shafyei, Powder Technol., 198, $412-416$ (2010).

11) S. J. Kiss, E. Kostic, D. Djurovic and S. Boskovic, Powder Technol., 114, 84-88 (2001).

12) S. L. Ni, L. Chou and J. Chang, Ceram. Int., 33, 93-98 (2007).

13) K. P. Sanosh, M. C. Chu, A. Balakrishnan, T. N. Kim and S. J. Cho, Bull. Mater. Sci., 32, 465-470 (2009).

14) M. B. D. Mitchel, D. Jackson and P. F. James, J. Non-Cryst. Solids, 225, 125-129 (1998).

15) L. Cheng, P. Chen, X. M. Chen, W. C. Niu, G. G. Yao, C. Liu, X. G. Zhao, Q. Liu and H. W. Zhang, J. Alloys Compd., 513, 373-377 (2012).

16) M. Kharaziha and M. H. Fathi, J. Mech. Behav. Biomed., 3, 530-537 (2010).

17) L. L. Hench, J. Am. Ceram. Soc., 74, 1487-1510 (2005). 